INNOVATIONS IN PRIMARY CARE

\title{
Interdisciplinary Group Visits for Patients With Complex Social Needs
}

\author{
M. Rebecca Hoffman, MD, MSPH \\ Meghan Golden, LCSW \\ Janice Frueh, PharmD ${ }^{1}$ \\ Nichole Mirocba, DO \\ Tracey Smith, DNP
}

Ann Fam Med 2020;18:83. https://doi.org/10.1370/afm.2467.

\section{THE INNOVATION}

To make a positive impact on patients who struggled to achieve improved health outcomes in the primary care setting, we redesigned our Federally Qualified Health Center's (FQHC) usual approach to outpatient services, developing a multidisciplinary team approach called the Comprehensive Care Clinic (CCC).

\section{WHO \& WHERE}

The CCC was developed in the Southern Illinois University (SIU) Center for Family Medicine, an FQHC in Springfield, Illinois. Building on previous collaborative work with student hotspotting (Supplemental Appendix at http://www.AnnFamMed.org/ content/18/1/83/suppl/DC1 and https://hotspotting.camdenhealth.org/), we developed an interprofessional team consisting of a family physician (MD/DO), pharmacist (PharmD), behavioral health provider (LCSW), public health nurse (DNP), community health workers (CHW), and psychiatrist (MD). Interprofessional learners and medical residents are also routinely involved.

\section{HOW}

Patients are recruited/engaged into the CCC through several pathways: community agencies (including the local police department, probation and treatment courts, and local shelters), patients who are already engaged in our student hotspotting program, and patients who are struggling with the usual clinic's care processes.

A team huddle occurs before each clinic, during which plans are made for which team members will see each patient, based on that patient's specific medical, psychiatric, and social needs.

Conflicts of interest: authors report none.

\section{Corresponding author}

M. Rebecca Hoffman, MD, MSPH

Department of Family and Community Medicine

sIU School of Medicine

520 N 4th St, Springfield, IL 62702

mhoffman51@siumed.edu
Several team members often see the patient during a CCC, and some may not need to see the patient at all; therefore, patients see different combinations of the nurse, physicians, pharmacist, resident or student learners, and behavioral health provider, often with the psychiatrist involved in case discussion without entering the room. Team members have received training in, and consistently utilize, patient-centered engagement techniques such as motivational interviewing, trauma informed care, accompaniment, and harm reduction. Approximately 10 patients are seen in each half-day clinic, with any team members who are not in the room during a patient encounter facilitating follow-up and delivery of services for patients as needed. There is an informal debriefing session following clinic.

We have been pleased to see that patients who had previously been labeled as "noncompliant" or "difficult" have successfully engaged in primary care services, and "no-show" occurrences are rare. Financial sustainability has been possible through traditional physician and mental health service reimbursement with both the physician and behavioral health providers billing separately, as well as CHW funding though grants; agreements with managed Medicaid for CHW services are now in place to maintain sustainability.

\section{LEARNING}

Replication of this model is possible in other primary care settings but requires careful selection of team members and a high level of enthusiasm. The team and clinical environment must be willing to "relax the rules" to help these patients succeed, and a non-judgmental attitude is paramount. Team members often cross the typical boundaries of their job descriptions, working in true interdisciplinary fashion. The CHW' role cannot be overemphasized, especially when it comes to continued patient engagement.

This team is unique in its composition and fluidity and has learned that it is essential to move beyond what are currently considered progressive and innovative models (such as traditional group visits, sequential provider visit models, and integrated behavioral health care) to meet the needs of patients with highest levels of complexity. We have found that it is not enough to have "on call" interdisciplinary team members; these individuals must all be present during visits and have in-depth conversations about patients together in order to close gaps in care and move quality of treatment to a higher level.

For additional information, including supplemental materials, key words, author affiliations, and funding support, see it online at http://www.AnnFamMed.org/content/18/1/83/suppl/DC1/. 